\title{
The Mechanics of Left Ventricular Contraction in Acute Experimental Cardiac Failure*
}

\author{
John Ross, Jr., † James W. Covell, and Edmund H. Sonnenblick \\ (From the Cardiology Branch, National Heart Institute, Bethesda, Md.)
}

Summary. The effects of acute cardiac failure induced by pentobarbital or pronethalol on the basic mechanical properties of the intact left ventricle were examined in the dog, and the influence on auxotonic and isovolumic contractions of the increase in end-diastolic volume that usually accompanies cardiac failure was assessed. The right heart bypass preparation was employed, and isovolumic beats were induced by sudden balloon occlusion of the aortic root. The ventricular pressure-volume curve was determined directly, and the mechanical responses of the myocardial fibers and contractile elements were calculated.

When end-diastolic pressure was held constant, failure reduced the extent of circumferential fiber shortening, and the tension-velocity relation calculated during isovolumic beats was always shifted, with reductions in both maximal velocity (average decrease $30 \%$ ) and maximal developed tension (average $23 \%$ ) ; in addition, during failure achievement of maximal contractile element velocity and maximal tension was delayed, whereas the total duration of contraction was always prolonged. Acetylstrophanthidin tended to reverse all of these changes. When end-diastolic volume was augmented during failure at a constant stroke volume, the extent of circumferential fiber shortening was reduced $(3.82 \mathrm{~cm}$ to $2.02 \mathrm{~cm})$, and during ejection the fiber and contractile element velocities were diminished at wall tensions comparable to control; maximal velocity and velocity at peak tension were also decreased. The tension-velocity relation during isovolumic beats was shifted by failure with consistent reductions in maximal shortening velocity, but changes in maximal tension were small. Maximal instantaneous power was always reduced by failure, and a striking alteration occurred in the relation between work expended in stretching the series elastic component and the external work; the former, "internal work," increased by an average of $90 \%$, the latter diminished by $11 \%$, and the total contractile element work remained essentially unchanged.

These findings are discussed within the framework of a three dimensional model that included fiber length, wall tension, and contractile element velocity. The experimental techniques employed appear to permit a more complete definition of the abnormalities of the ventricular myocardium in experimental failure. They are potentially applicable in the closed-chest animal and allow quantitative determinations of the contractile properties of the left ventricle.

\section{Introduction}

The pattern of left ventricular contraction in cardiac failure has not been subjected to detailed

* Submitted for publication July 15, 1966; accepted November 3, 1966. analysis in terms analogous to those which describe the mechanical properties of isolated muscle.

$\dagger$ Address requests for reprints to Dr. John Ross, Jr., Cardiology Branch, National Heart Institute, Bethesda, Md. 20014. 
Previously, attention has centered primarily on the changes in intracardiac pressure and external cardiac work that accompany heart failure, measures that do not provide direct information concerning myocardial fiber length, wall tension, or the time-dependent phenomena of contraction; moreover, pressure and work may be influenced markedly by a variety of extracardiac factors. Determination of the relation between ventricular filling pressure and stroke work over a range of filling pressures expands the utility of this relation in a given experimental animal $(1,2)$, but has proved impractical in the intact animal, or in man, largely because of the rapid, reflex circulatory adjustments that accompany infusions of blood or plasma expanders (3). In addition, this approach does not offer the possibility of quantitative comparison of ventricular contraction properties among different animals. It was considered, therefore, that a more promising avenue to the characterization of ventricular contraction in heart failure might lie in an analysis of several basic mechanical properties of the ventricular myocardium, i.e., the extent of muscle fiber and contractile element shortening, the instantaneous relations between shortening velocity and myocardial wall tension, the maximal tension attainable from a given resting fiber length, and the work of the contractile elements. Partial assessment of these factors has been possible previously in a dog prep-

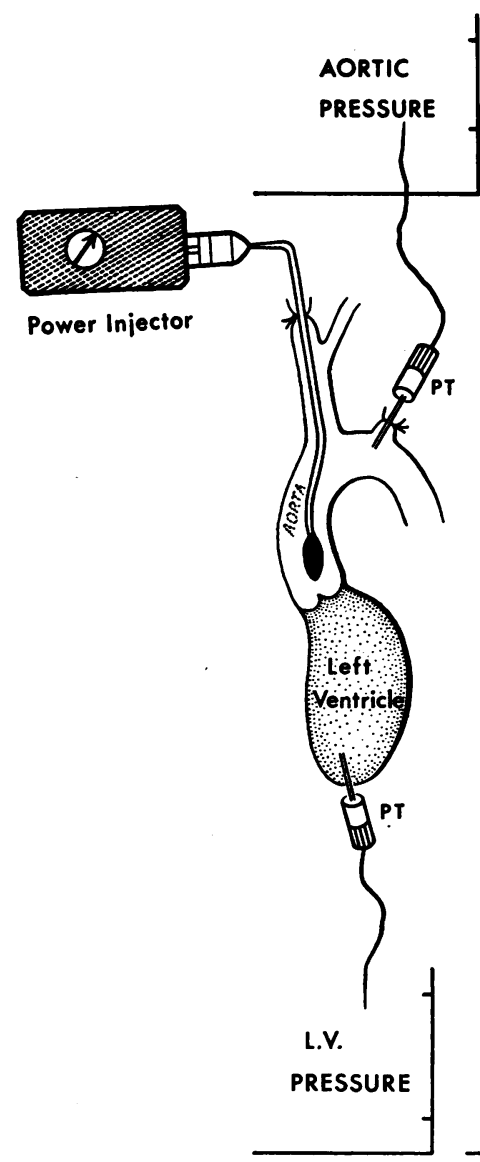

A,
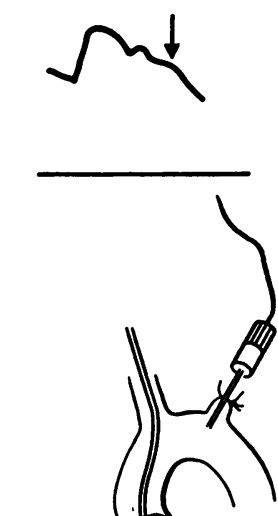

Balloon
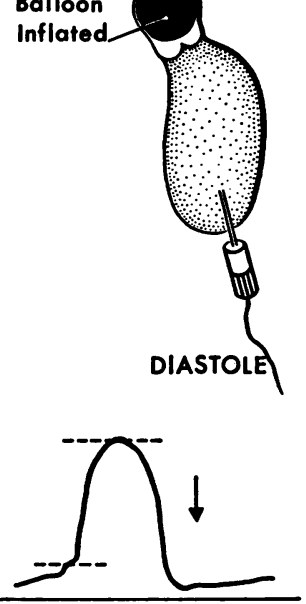

B.

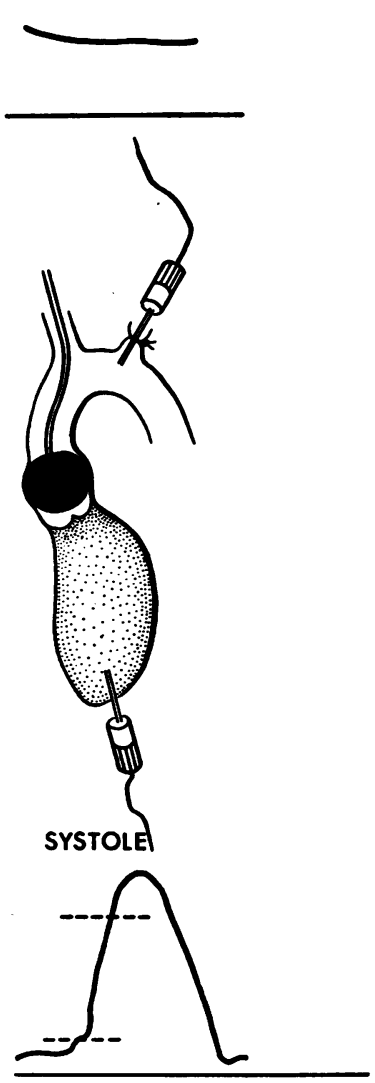

C.

Fig. 1. Diagram of the technigue USEd for producing isovolumic contractions. Panel A : Arrangement of the power syringe, cannula, and balloon. PT = pressure transducer. Panel B: Simultaneously recorded aortic pressure (upper tracing) and left ventricular (LV) pressure (lower tracing). At the arrow, the balloon is suddenly inflated during diastole. Panel C: Tracings showing the ensuing contraction, which is isovolumic and originates from the same end-diastolic pressure (lower dotted horizontal line). 
aration that allowed the production of variably afterloaded left ventricular contractions (4), and some of the findings have been presented in preliminary form (5).

The present studies were undertaken to examine in detail the effects of acute, drug-induced cardiac failure on the pattern of left ventricular contraction during normal (auxotonic) and isovolumic beats and to define the influence on such contractions of the augmentation in ventricular end-diastolic volume that usually accompanies cardiac failure. The methods of analysis used are potentially applicable to quantitative studies in the closed-chest animal, and the experimental results therefore provide a framework for investigation of the mechanics of left ventricular contraction in chronic, or naturally occurring, myocardial failure.

\section{Methods}

Studies were performed in 11 dogs, weighing between 15.0 and $19.5 \mathrm{~kg}$. The animals were anesthetized with sodium pentobarbital (average dose $40 \mathrm{mg}$ per $\mathrm{kg}$ ), the trachea was intubated, and ventilation was provided with a Harvard respiratory pump using $100 \%$ oxygen. The basic experimental preparation has been described previously (6) ; in brief, a bilateral thoracotomy was performed, the heart was suspended in a pericardial cradle, and the right heart was bypassed with an occlusive pump. Heart rate was maintained constant by electrical stimu- lation of the right atrium after crush of the sinoatrial node, and systemic arterial pressure was regulated by means of a pressure bottle attached to the femoral artery. Temperature was maintained constant between 35 and $37^{\circ}$ $\mathrm{C}$ with a heat exchanger. A balloon-tipped cannula was inserted into the root of the aorta, its tip being positioned in the sinus of Valsalva, and sudden inflation of the balloon permitted occlusion of the aortic root during a single diastolic interval (Figure 1) (7).

Aortic and left ventricular pressures were measured through large bore metal cannulae inserted via the left subclavian artery and left ventricular (LV) apex and connected directly to Statham P23Db transducers. The first derivative of the $L V$ pressure pulse $(\mathrm{LV} \mathrm{dp} / \mathrm{dt})$ was obtained with an analog differentiating circuit ${ }^{1}$ that exhibited a phase shift of $90^{\circ} \pm 1^{\circ}$ to a sine wave input from 0 to $160 \mathrm{cps}$, amplitude being a linear function of frequency. A flow transducer was placed around the ascending aorta, and instantaneous LV ejection rate was measured with a gated sine wave electromagnetic flowmeter ${ }^{2}$ the dynamic characteristics of which have been described (4). The occlusive pump employed for bypass of the right heart was used to calibrate the flowmeter, with the flow transducer in situ. All measurements were recorded together with the electrocardiogram on a multichannel oscillograph ${ }^{3}$ at a paper speed of $100 \mathrm{~mm}$ per second.

As described previously, the diastolic pressure-volume

1 Assembled by Electronic Gear, Valley Stream, N. Y., from a Philbrick no. P65AU operational amplifier.

2 Biotronex, Silver Spring, Md.

3 Model 350, Sanborn, Cambridge, Mass.

TABLE I

Acute ventricular failure with constant end-diastolic pressure*

\begin{tabular}{|c|c|c|c|c|c|c|c|c|c|c|c|c|c|}
\hline $\begin{array}{c}\text { Dog } \\
\text { no. }\end{array}$ & Intervention & LVEDP & MAP & $\underset{d p / d t}{L V}$ & PAF & $\underset{\text { vol }}{\text { LVED }}$ & SV & $\begin{array}{l}\text { ED } \\
\text { circ }\end{array}$ & $\Delta \mathrm{L}_{\mathrm{CF}}$ & $\underset{\text { Maxi- }}{\operatorname{mal}}$ & $\mathrm{P}_{0}$ & $\begin{array}{l}\text { Time } \\
\text { to } \mathrm{P}_{0}\end{array}$ & $\begin{array}{l}\text { LV } \\
\text { dur }\end{array}$ \\
\hline & & $\stackrel{m m}{H g}$ & $\stackrel{m m}{H g}$ & $\underset{s e c}{m \boldsymbol{H}} \boldsymbol{H g}$ & $\mathrm{ml} / \mathrm{sec}$ & $m l$ & $m l$ & $\mathrm{~cm}$ & $\mathrm{~cm}$ & $\begin{array}{l}\mathrm{cm} / / \\
\mathrm{sec} / \\
\mathrm{circ}\end{array}$ & $g / c i r c$ & $m s e c$ & msec \\
\hline 1 & C & $\begin{array}{l}5.0 \\
5.2\end{array}$ & $\begin{array}{l}75 \\
68\end{array}$ & $\begin{array}{l}2,540 \\
2,030\end{array}$ & $\begin{array}{l}159 \\
132\end{array}$ & $\begin{array}{l}17.9 \\
18.4\end{array}$ & $\begin{array}{l}11.4 \\
10.3\end{array}$ & $\begin{array}{l}10.3 \\
10.2\end{array}$ & $\begin{array}{l}3.11 \\
2.43\end{array}$ & $\begin{array}{l}2.20 \\
2.13\end{array}$ & $\begin{array}{l}198 \\
176\end{array}$ & $\begin{array}{l}120 \\
130\end{array}$ & $\begin{array}{l}310 \\
320\end{array}$ \\
\hline 2 & $\stackrel{\mathrm{C}}{\mathrm{F}}(\mathrm{P})$ & $\begin{array}{l}2.5 \\
2.5\end{array}$ & $\begin{array}{l}62 \\
65\end{array}$ & $\begin{array}{l}1,675 \\
1,490\end{array}$ & $\begin{array}{r}111 \\
90\end{array}$ & $\begin{array}{l}16.7 \\
16.7\end{array}$ & $\begin{array}{l}8.6 \\
5.2\end{array}$ & $\begin{array}{l}9.96 \\
9.96\end{array}$ & $\begin{array}{l}2.13 \\
1.16\end{array}$ & $\begin{array}{l}1.81 \\
1.07\end{array}$ & $\begin{array}{l}132 \\
118\end{array}$ & $\begin{array}{l}125 \\
155\end{array}$ & $\begin{array}{l}280 \\
310\end{array}$ \\
\hline 3 & $\stackrel{\mathrm{C}}{\mathrm{F}}(\mathrm{P})$ & $\begin{array}{l}2.0 \\
2.0\end{array}$ & $\begin{array}{r}105 \\
75\end{array}$ & $\begin{array}{l}3,660 \\
2,360\end{array}$ & $\begin{array}{r}110 \\
62\end{array}$ & $\begin{array}{l}16.0 \\
16.0\end{array}$ & $\begin{array}{l}8.2 \\
5.8\end{array}$ & $\begin{array}{l}9.82 \\
9.82\end{array}$ & $\begin{array}{l}2.09 \\
1.37\end{array}$ & $\begin{array}{l}2.12 \\
1.36\end{array}$ & $\begin{array}{l}184 \\
145\end{array}$ & $\begin{array}{l}135 \\
145\end{array}$ & $\begin{array}{l}290 \\
320\end{array}$ \\
\hline 4 & $\stackrel{\mathrm{C}}{\mathrm{F}}(\mathrm{P})$ & $\begin{array}{l}7.0 \\
7.0\end{array}$ & $\begin{array}{l}70 \\
79\end{array}$ & $\begin{array}{l}1,895 \\
1,615\end{array}$ & $\begin{array}{r}109 \\
90\end{array}$ & $\begin{array}{l}21.3 \\
21.3\end{array}$ & $\begin{array}{r}13.4 \\
8.5\end{array}$ & $\begin{array}{l}10.1 \\
10.1\end{array}$ & $\begin{array}{l}3.04 \\
1.68\end{array}$ & $\begin{array}{l}1.65 \\
1.29\end{array}$ & $\begin{array}{l}202 \\
170\end{array}$ & $\begin{array}{l}145 \\
150\end{array}$ & \\
\hline 5 & $\begin{array}{l}\mathrm{C} \\
\mathbf{F}(\mathrm{N}) \\
\mathbf{R}(\mathrm{ACS})\end{array}$ & $\begin{array}{l}4.8 \\
5.2 \\
5.0\end{array}$ & $\begin{array}{l}73 \\
77 \\
70\end{array}$ & $\begin{array}{l}1,570 \\
1,010 \\
2,015\end{array}$ & $\begin{array}{r}120 \\
58 \\
152\end{array}$ & $\begin{array}{l}15.0 \\
15.8 \\
15.2\end{array}$ & $\begin{array}{r}10.6 \\
4.2 \\
13.0\end{array}$ & $\begin{array}{l}9.43 \\
9.78 \\
9.65\end{array}$ & $\begin{array}{l}3.04 \\
0.96 \\
4.58\end{array}$ & $\begin{array}{l}1.72 \\
1.26 \\
1.90\end{array}$ & $\begin{array}{l}148 \\
109 \\
183\end{array}$ & $\begin{array}{l}130 \\
150\end{array}$ & $\begin{array}{l}340 \\
360 \\
295\end{array}$ \\
\hline 6 & $\begin{array}{l}\mathrm{C} \\
\mathbf{F}(\mathrm{N}) \\
\mathrm{R}(\mathrm{ACS})\end{array}$ & $\begin{array}{l}3.5 \\
3.5 \\
3.0\end{array}$ & $\begin{array}{l}80 \\
80 \\
86\end{array}$ & $\begin{array}{l}2,570 \\
1,180 \\
1,820\end{array}$ & $\begin{array}{r}151 \\
72 \\
107\end{array}$ & $\begin{array}{l}12.0 \\
12.0 \\
11.0\end{array}$ & $\begin{array}{l}7.5 \\
3.5 \\
4.4\end{array}$ & $\begin{array}{l}8.92 \\
8.92 \\
8.67\end{array}$ & $\begin{array}{l}2.48 \\
0.96 \\
1.34\end{array}$ & $\begin{array}{l}1.14 \\
0.53 \\
0.83\end{array}$ & $\begin{array}{l}188 \\
113 \\
144\end{array}$ & $\begin{array}{l}135 \\
145\end{array}$ & $\begin{array}{l}300 \\
340 \\
310\end{array}$ \\
\hline 7 & $\begin{array}{l}\mathrm{C} \\
\mathrm{F}(\mathrm{N}) \\
\mathrm{R}(\mathrm{ACS})\end{array}$ & $\begin{array}{l}6.0 \\
6.0 \\
6.0\end{array}$ & $\begin{array}{l}79 \\
80 \\
80\end{array}$ & $\begin{array}{l}1,995 \\
1,035 \\
2,510\end{array}$ & $\begin{array}{l}184 \\
102 \\
229\end{array}$ & $\begin{array}{l}52.0 \\
52.0 \\
52.0\end{array}$ & $\begin{array}{r}23.0 \\
9.5 \\
25.0\end{array}$ & $\begin{array}{l}14.5 \\
14.5 \\
14.5\end{array}$ & $\begin{array}{l}2.57 \\
0.94 \\
2.85\end{array}$ & $\begin{array}{l}1.65 \\
0.96 \\
1.85\end{array}$ & $\begin{array}{l}258 \\
167 \\
279\end{array}$ & $\begin{array}{l}155 \\
190\end{array}$ & $\begin{array}{l}350 \\
385 \\
350\end{array}$ \\
\hline
\end{tabular}

* $C=$ control state $;=$ failure, induced by pentobarbital $(P)$ or pronethalol $(N) ; R=$ recovery period; ACS $=$ acetylstrophanthidin LVEDP = left ventricular end-diastolic pressure and MAP $=$ mean aortic pressure $;$ PAF $=$ peak aortic flow rate $;$ SV $=$ stroke volume $;$ ED circ $=$ end-diastolic circumference at internal equator; $\Delta \mathrm{LCF}=$ change in length of the internal equator with shortening of the circumferential fibers $\mathrm{VCE}=$ measured contractile element velocity (see text); $\mathrm{P}_{0}=$ maximal isovolumic tension; time to $\mathrm{P}_{0}=$ time from end of diastole to $\mathrm{P}_{0} ; \mathrm{LV}$ dur
$=$ duration of isovolumic LV contractions from onset of contraction until end of relaxation, ascertained from the LV pressure tracing. 


\begin{tabular}{|c|c|c|c|c|c|c|c|c|c|c|c|}
\hline \multirow[b]{2}{*}{$\begin{array}{l}\text { Dog } \\
\text { no. }\end{array}$} & \multirow[b]{2}{*}{$\begin{array}{c}\text { Inter- } \\
\text { vention }\end{array}$} & \multirow[b]{2}{*}{ LVEDP } & \multirow[b]{2}{*}{ MAP } & \multirow[b]{2}{*}{$\begin{array}{c}\mathrm{LV} \\
\mathrm{dp} / \mathrm{dt}\end{array}$} & \multirow[b]{2}{*}{ PAF } & \multirow[b]{2}{*}{$\underset{\text { vol }}{\text { LVED }}$} & \multirow[b]{2}{*}{$\begin{array}{l}\text { ED } \\
\text { circ }\end{array}$} & \multicolumn{4}{|c|}{ Auxotonic contractions } \\
\hline & & & & & & & & $\begin{array}{l}\text { Time } \\
\text { to } \mathrm{P}_{0}\end{array}$ & 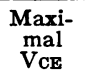 & $\begin{array}{l}\text { VCE } \\
\text { at P }\end{array}$ & $\begin{array}{l}\text { CcF at } \\
\text { iso } P\end{array}$ \\
\hline & & $m m H g$ & $m m H g$ & $\underset{s e c}{m m H g l}$ & $m l / s e c$ & $m l$ & $\mathrm{~cm}$ & $m s e c$ & \multicolumn{3}{|c|}{$\mathrm{cm} / \mathrm{sec} / \mathrm{circ}$} \\
\hline 7 & $\mathrm{C}$ & 3.5 & 80 & 1,920 & 159 & 41.0 & 13.5 & 120 & 1.6 & 1.5 & 1.2 \\
\hline & $\mathrm{F}(\mathrm{N})$ & 15.0 & 74 & 1,110 & 155 & 69.0 & 16.0 & 175 & 1.0 & 0.7 & 0.5 \\
\hline \multirow[t]{2}{*}{8} & C & 3.8 & 80 & 3,270 & 227 & 21.4 & 10.8 & 95 & 4.0 & 3.3 & 3.3 \\
\hline & $F(N)$ & 14.0 & 80 & 1,295 & 134 & 46.0 & 14.0 & 150 & 1.0 & 1.0 & 0.75 \\
\hline \multirow[t]{2}{*}{9} & C & 4.5 & 83 & 3,925 & 165 & 19.6 & 10.5 & 80 & 5.6 & 3.7 & 5.0 \\
\hline & $\mathrm{F}(\mathrm{P})$ & 14.5 & 80 & 1,750 & 115 & 34.7 & 12.7 & 135 & 1.4 & 1.4 & 1.4 \\
\hline \multirow[t]{2}{*}{10} & C & 3.5 & 82 & 3,225 & 77 & 18.0 & 10.2 & 105 & 2.0 & 2.0 & 2.0 \\
\hline & $F(P)$ & 14.0 & 78 & 1,725 & 69 & 47.6 & 14.1 & 150 & 0.5 & 1.5 & 0.35 \\
\hline \multirow[t]{2}{*}{11} & C & 3.5 & 77 & 2,350 & 166 & 22.3 & 11.0 & 100 & 5.7 & 3.7 & 3.4 \\
\hline & $F(P)$ & 11.8 & 77 & 1,175 & 134 & 56.0 & 14.9 & 150 & 1.0 & 1.0 & 0.52 \\
\hline
\end{tabular}

* Abbreviations as in Table $\mathrm{I}$. In addition, $\mathrm{P}=$ maximal auxotonic ventricular tension; $\mathrm{V}_{\mathrm{CF}}$ at iso $\mathrm{P}=\mathrm{V}_{\mathrm{CF}}$ compared at the same wall tensions during control and failing auxotonic beats. $\mathrm{SE}=$ series elastic component; $\mathrm{SE}$ work $=$ work done in stretching the $\mathrm{SE}$ component; net $\mathrm{SE}$ work = work done in stretching the SE component minus $\mathrm{SE}$ recoil work.

curve of the ventricle was determined immediately at the conclusion of each experiment by arresting the heart with potassium, occluding the aortic and mitral valves, and filling the cavity with 2-ml increments of fluid; from this curve the left ventricular end-diastolic volume for each contraction during the experiment was determined (4). The methods for calculation of tension-velocity relations, which have been detailed elsewhere $(4,7)$, in principle resemble those previously employed by Fry, Griggs, and Greenfield (8) and Levine and Britman (9). In brief, during single isovolumic beats, or during the isovolumic phase of ejecting beats, contractile element velocity ( $V_{C E}$ ) was considered equal to the rate of lengthening ( $\mathrm{dl} / \mathrm{dt})$ of the series elastic component, $\mathrm{dl} / \mathrm{dt}$ being considered directly proportional to the rate of tension development $(\mathrm{dT} / \mathrm{dt})$ and inversely proportional to the stiffness of the series elastic component (dT/dl) (10). Tangential tension in the myocardial wall was calculated from the LaPlace relation, assuming a spherical left ventricular model. The isovolumic tension-velocity relation consisted of the instantaneous relations between wall tension and $V_{\text {Cr }}$ plotted at $10-$ msec intervals from maximal measured $V_{c x}$ to maximal tension $\left(P_{0}\right)$; maximal velocity $\left(V_{\max }\right)$ can be estimated only by extrapolation from these curves, and therefore the maximal $V_{C x}$ for comparison reported in the Tables during control and failure states are those measured at the lowest common tension. $\mathrm{V}_{\max }$ during the control periods was determined by extrapolating to zero tension the isovolumic tension-velocity relation of two contractions originating from a slightly different end-diastolic volume. Since in some of the present experiments, in contrast to previous studies, changes in left ventricular end-diastolic volume were permitted to occur, tension and velocity measurements have been normalized by dividing by ventricular circumference. Exceptions to this normalization are the power curves, which were constructed by determining the instantaneous product of circumferential contractile element or fiber shortening velocity and total tension at the internal ventricular equator; contractile element work (CEW) (11) per beat was determined by integrating the power curves. Resting tension has not been subtracted, except in Figure 5, where active tension (developed tension minus resting tension) is also shown for comparison. $V_{\mathrm{CE}}$, myocardial wall tension, contractile element power, and contractile element work were also determined at 10 -msec intervals during auxotonic contractions; as previously, $V_{C E}$ during ejection was determined as the sum of the external fiber shortening rate $\left(V_{c r}\right)$ and the rate of lengthening of the series elastic component (4). The extent of external shortening of the circumferential ventricular fibers of the internal equator $\left(\Delta \mathrm{L}_{\mathrm{CF}}\right)$ has been expressed both as total shortening distance and as shortening per circumference. The peak myocardial wall tension during auxotonic contractions has been termed $P$, and $P / P_{0}$ refers to the ratio of $P$ to the maximal tension achieved during an isovolumic beat $\left(P_{0}\right)$, induced at the same ventricular end-diastolic pressure and level of contractile state.

The experiments were performed according to the following general plan: Control auxotonic and isovolumic contractions were recorded at a relatively normal level of cardiac output and left ventricular end-diastolic pressure (LVEDP). Acute heart failure was then induced either by the administration of pentobarbital (average dose $=12 \mathrm{mg}$ per $\mathrm{kg}$ per minute) or by the administration of the beta-adrenergic blocking agent pronethalol (average dose $=2.1 \mathrm{mg}$ per $\mathrm{kg}$ ), which is known to exert a direct depressant effect on the myocardium in addition to its sympatholytic action $(12,13)$. In these experiments (experiments 1 through 7 ) as acute failure of the left ventricle occurred, elevation of the left ventricular filling pressure was prevented, and left ventricular end-diastolic pressure was maintained constant by 
TABLE II

increased end-diastolic pressure*

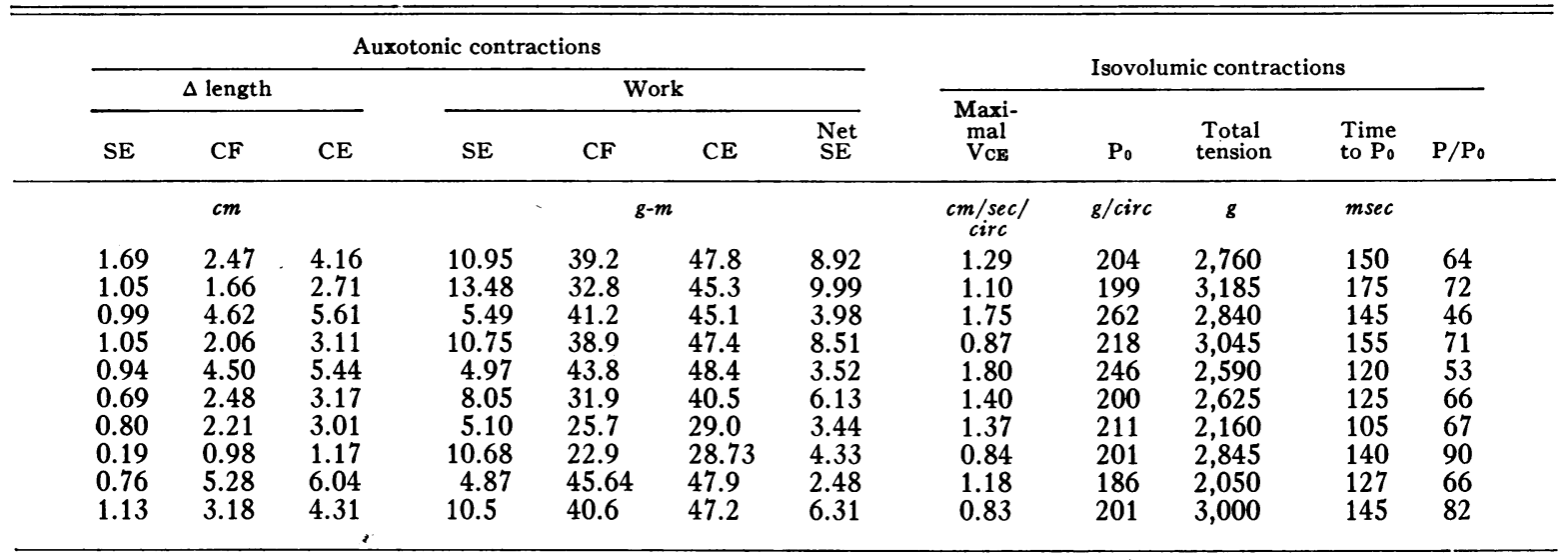

reducing the output of the pump. During a steady state, isovolumic and auxotonic relations were then recorded again during acute heart failure, at the same end-diastolic volume as during the control state. In 3 dogs, acetylstrophanthidin $(0.044 \mathrm{mg}$ per $\mathrm{kg})$ was then administered, and auxotonic and isovolumic contractions were recorded approximately 20 minutes later. In experiments 7 through 11 the output of the pump, and hence the stroke volume, were maintained constant during the induction of acute heart failure, and the LVEDP therefore increased. In these experiments, pentobarbital and pronethalol were infused over an interval of 25 to 40 minutes, and the total doses averaged $58 \mathrm{mg}$ per $\mathrm{kg}$ and $22 \mathrm{mg}$ per $\mathrm{kg}$, respectively. Auxotonic and isovolumic contractions were again recorded during the steady state, when the LVEDP was well above the normal level.

\section{Results}

The experiments in which end-diastolic pressure was held constant during acute ventricular failure are summarized in Table $I$, and those in which end-diastolic pressure was permitted to increase during failure are shown in Table II.

I) Acute left ventricular failure with end-diastolic pressure constant

A) Auxotonic contractions. During the control state, LVEDP averaged $4.4 \mathrm{~mm} \mathrm{Hg}$ (range 2 to $7 \mathrm{~mm} \mathrm{Hg}$ ) and varied by no more than 0.5 $\mathrm{mm} \mathrm{Hg}$ during any experiment. During acute cardiac failure, the indirect measures of ventricular contractility were reduced, maximal flow rate in the ascending aorta falling by an average of $36 \%$, LV dp/dt being reduced by an average of $33 \%$, and the ratio of stroke volume to end-dia- stolic volume decreasing from an average value of $58 \%$ to $34 \%$. Since LVEDP was constant, calculated LV end-diastolic circumference was essentially unchanged before and during cardiac failure (average circumference $=10.4 \mathrm{~cm}$, range $=8.92$ to $14.5 \mathrm{~cm}$ ). The change in the end-diastolic circumference during ejection was reduced by acute heart failure in each experiment, the change averaging $2.64 \mathrm{~cm}$ before and $1.36 \mathrm{~cm}$ during failure; the average percentage shortening of the circumference was $26 \%$ in the control state and $13 \%$ during acute failure.

$B)$ Isovolumic contractions. Representative tracings recorded during the production of isovolumic contractions are shown in Figure 2 . Shifts downward and to the left of the tensionvelocity relations calculated from such isovolumic contractions always occurred during acute heart failure (Table I, Figures 2 and 3). Maximal measured $V_{C E}$ averaged $1.76 \mathrm{~cm}$ per second per circumference (range 1.14 to $2.20 \mathrm{~cm}$ per second per circumference) before and $1.23 \mathrm{~cm}$ per second per circumference (range 0.53 to $2.13 \mathrm{~cm}$ per second per circumference) during failure $[\mathrm{p}<0.01$, paired $t$ test (14)]. Maximal isovolumic tension $\left(\mathrm{P}_{0}\right)$ was also decreased in each experiment during failure, the values averaging $187 \mathrm{~g}$ per circumference (range 132 to $258 \mathrm{~g}$ per circumference) in the control state and $142 \mathrm{~g}$ per circumference (range 113 to $176 \mathrm{~g}$ per circumference) during failure.

The time course of contractile element velocity 

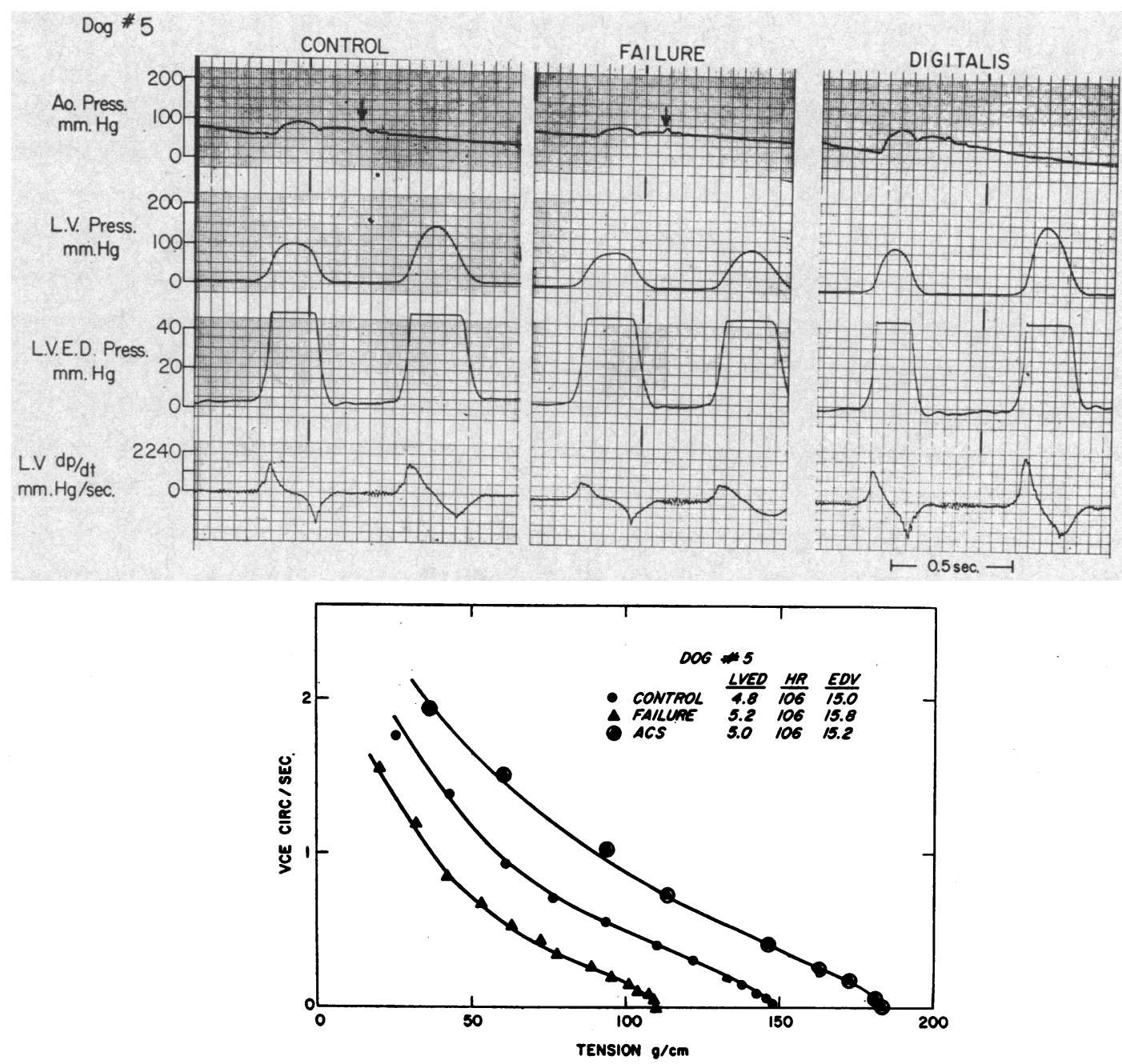

Fig. 2. Pressures recorded in the central aorta (ao. press.) and left ventricle (LV) at low AND AT HIGH SENSITIVITY (LVED), TOGETHER WITH THE FIRST DERIVATIVE OF THE VENTRICULAR TRACING (LV DP/DT). The arrows and small deflections on the aortic pressure tracings during diastole indicate the time at which the balloon was inflated.

The lower panel shows the tension-velocity relations calculated from the isovolumic contractions shown in the tracings (the second beat in each of the 3 upper panels). V $\mathbf{c E}=$ contractile element velo:ity; $\operatorname{circ}=$ end-diastolic circumference at internal equator; $\mathrm{HR}=$ heart rate $\mathrm{EDV}=$ end-diastolic volume; ACS $=$ acetylstrophanthidin.

and tension during isovolumic contractions before and during failure is shown in Figure 3. During cardiac failure, maximal $\mathrm{V}_{\mathbf{C E}}$ and maximal tension were achieved later, while the total duration of isovolumic contraction was consistently prolonged, averaging $312 \mathrm{msec}$ (range 280 to $350 \mathrm{msec}$ ) during the control state and 339 msec (range 310 to $385 \mathrm{msec}$ ) during acute failure $(\mathrm{p}<0.01)$. Time to maximal $\mathrm{P}_{0}$ averaged 135 msec (range 120 to $155 \mathrm{msec}$ ) in the control state and $152 \mathrm{msec}$ (range 130 to $190 \mathrm{msec}$ ) during failure.

Administration of acetylstrophanthidin in 3 animals tended to return all of these measurements toward the control levels (Table I, Figure 3).

\section{II) Left ventricular end-diastolic pressure in- creased}

A) Auxotonic contractions. In the experiments in which stroke volume was constant and 

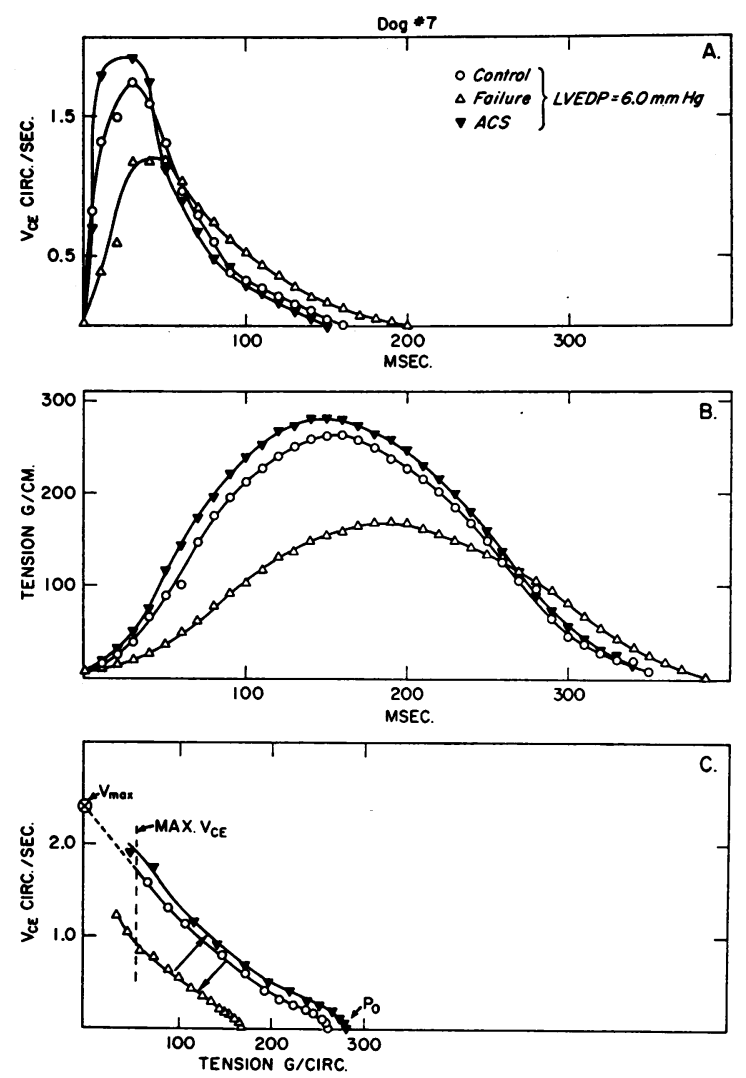

Fig. 3. Time course of V (PANEL B) DURING THE CONTROL STATE, ACUTE HEART FaIlure, AND ACS administration. Panel C illustrates the tension-velocity relations for these 3 contractions; the vertical dashed line indicates the lowest common tension at which maximal $V_{C E}$ was measured. Maximal velocity $\left(V_{\max }, \otimes\right)$ represents the average extrapolation of 2 control contractions originating from slightly different left ventricular end-diastolic pressures (LVEDP). $P_{0}$ is maximal isovolumic tension.

LVEDP was permitted to increase, the control values for LVEDP averaged $3.8 \mathrm{~mm} \mathrm{Hg}$ (range 3.5 to $4.5 \mathrm{~mm} \mathrm{Hg}$ ), and during acute heart failure they averaged $13.9 \mathrm{~mm} \mathrm{Hg}$ (range 11.8 to 15.0 $\mathrm{mm} \mathrm{Hg}$ ) (Table II). Maximal aortic flow rate was decreased during failure by an average of $24 \%$, and the left ventricular $\mathrm{dp} / \mathrm{dt}$ fell, the average decrease being $51 \%$. The calculated enddiastolic circumference of the left ventricle was increased from an average control value of $11.2 \mathrm{~cm}$ to $14.3 \mathrm{~cm}$ during acute heart failure, and the shortening of the circumference during ejection was always reduced, averaging $3.82 \mathrm{~cm}$ (range 2.21 to $5.28 \mathrm{~cm}$ ) during control contractions and $2.07 \mathrm{~cm}$ (range 0.98 to $3.18 \mathrm{~cm}$ ) during failure.
The time course of $\mathrm{V}_{\mathrm{CF}}, \mathrm{V}_{\mathrm{CE}}$, and tension during a control contraction and during failure when LVEDP was elevated is plotted in Figure 4, panels $A$ and $B$. The tension-velocity relations during the same 2 auxotonic contractions are shown in Figure 4, panels $C$ and $D$, the tensionvelocity relations for the isovolumic contractions originating from the same LVEDP being represented by dashed lines. Similar plots were obtained in all 5 experiments (Table II). During ejection, the levels of $\mathrm{V}_{\mathrm{CF}}$ at comparable wall tensions were always reduced, the average decrease being $68 \%$ (range 58 to $92 \%$ ) (Table II) ; similarly, the corresponding values for $\mathrm{V}_{\mathrm{CE}}$ were reduced by an average of $66 \%$ (range 50 to $73 \%$ ). The maximal $\mathrm{V}_{\mathrm{CE}}$ during ejection was also always reduced by failure, the range in the control state being 1.6 to $5.7 \mathrm{~cm}$ per second per circumference (average $3.8 \mathrm{~cm}$ per second per circumference), whereas during failure the maximal $\mathrm{V}_{\mathrm{CE}}$ ranged from 0.5 to $1.4 \mathrm{~cm}$ per second per circumference (average $0.98 \mathrm{~cm}$ per second per circumference); the average percentage decrease equaled $69 \%$.

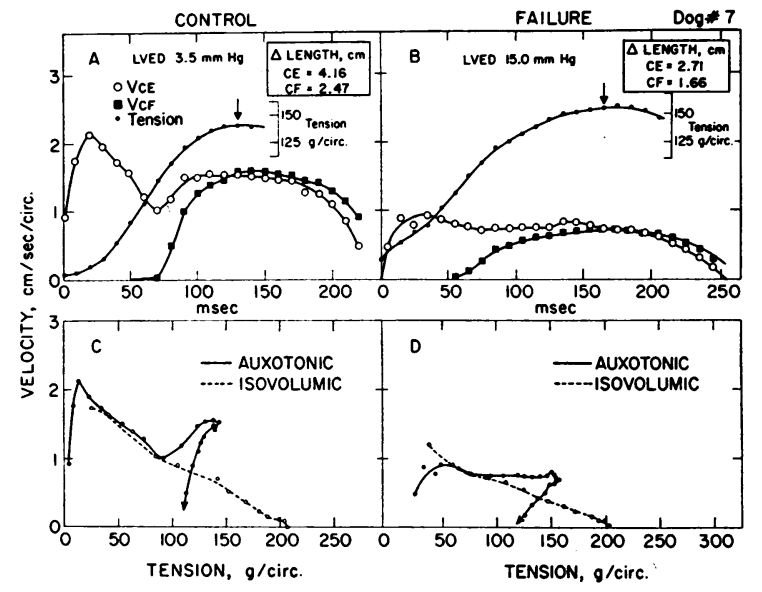

Fig. 4. RELATIONS BETWEEN SHORTENING VELOCITY AND TENSION BEFORE (LEFT PANELS) AND DURING (RIGHT PANELS) ACUTE FAILURE WHEN LEFT VENTRICUAR ENDDIASTOLIC PRESSURE (LVED) WAS ELEVATED. The upper panels show the temporal relation of $\mathrm{V}_{\mathrm{CE}}$ to tension, the latter being plotted through peak tension (vertical arrows). $\Delta$ length (insert) refers to the change in circumference of the fibers (CF) at the internal equator during ejection and to the calculated extent of shortening of the contractile elements (CE) during systole. The lower panels show the tension-velocity $\left(\mathrm{V}_{\mathrm{CE}}\right)$ relations in auxotonic and isovolumic beats originating from the same LVED pressure in the control (panel C) and the failure state (panel D). 
The $\mathrm{V}_{\mathrm{CE}}$ at maximal tension during ejection ( $\mathrm{P}$ ), when $V_{C E}$ and $V_{C F}$ were equal, was also reduced, the average decrease being $57 \%$ (Table II).

$B)$ Isovolumic contractions. The features of the isovolumic force-velocity relation before and during acute heart failure when LVEDP was permitted to increase are summarized in Table II, and representative curves are shown in Figure 5. In all experiments estimated $V_{\max }$ during failure appeared reduced when compared with the $\mathrm{V}_{\max }$ averaged for 2 control beats (Figure 5). The values for maximal $V_{C E}$ at comparable wall tensions were also reduced, averaging $1.48 \mathrm{~cm}$ per second per circumference (range 1.18 to $1.80 \mathrm{~cm}$ per second per circumference) in the control state and $1.01 \mathrm{~cm}$ per second per circumference (range

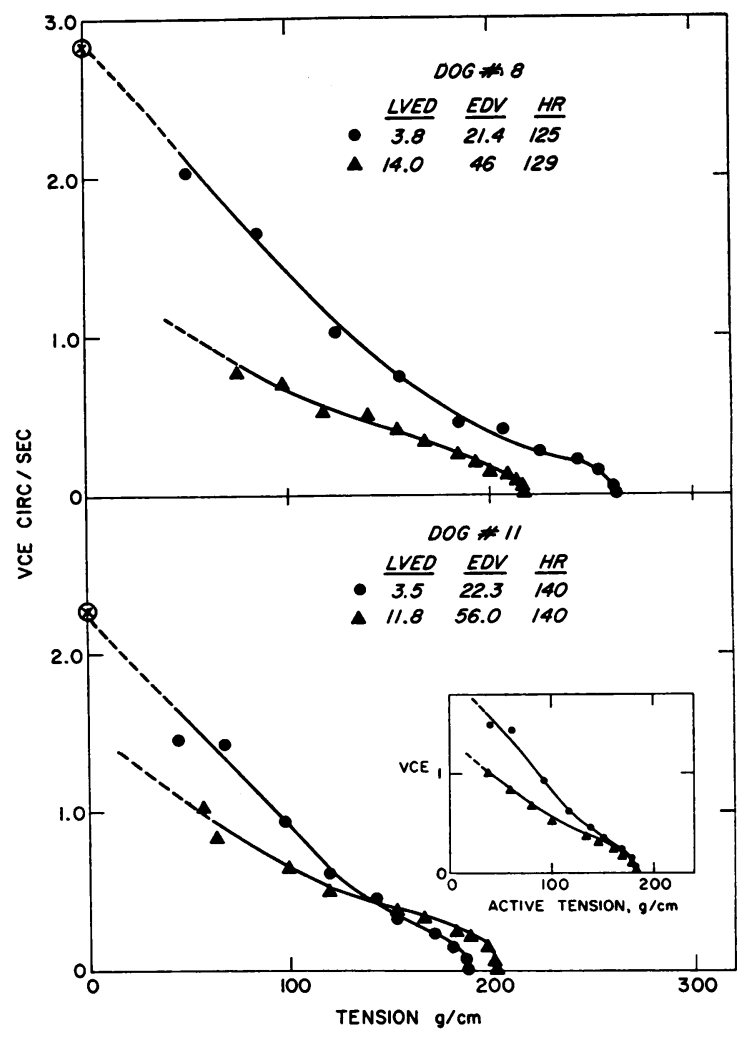

Fig. 5. Tension-velocity Relations in 2 animals BEFORE AND DURING ACUTE FAILURE WHEN LVED PRESSURE (MILLIMETERS HG) WAS ELEVATED. EDV is in milliliters. In the upper panel, both maximal tension, in grams per circumference, and the extrapolation to $\mathrm{V}_{\max }$ $(\otimes)$ are reduced. In the lower panel, maximal tension is slightly elevated, whereas $\mathrm{V}_{\max }$ is reduced; in the insert, the same experiment is shown with active tension plotted on the abscissa, and no increase in $\mathrm{P}_{0}$ is observed.
0.83 to $1.40 \mathrm{~cm}$ per second per circumference) during failure $(\mathrm{p}<0.02)$. When calculated as tension per unit circumference, $\mathrm{P}_{0}$ decreased by an average of $12 \%$ (range 2 to $23 \%$ ) in 4 experiments and increased by $8 \%$ in one experiment (Table II). In the latter experiment (Figure 5), when active tension was plotted for comparison, $\mathrm{P}_{0}$ showed no change during failure. Total tension developed at the equator increased in all 5 experiments (average increase $=15 \%) \quad($ Table II).

As in the experiments in which end-diastolic volume was constant, the time to maximal isovolumic tension $\left(\mathrm{P}_{0}\right)$ was delayed during failure at an elevated LVEDP; during the control state, time to maximal tension averaged $129 \mathrm{msec}$ (range 105 to $150 \mathrm{msec}$ ), and during failure these values averaged $148 \mathrm{msec}$ (range 125 to $175 \mathrm{msec}, \mathrm{p}<0.05$ ).

C) Relations between auxotonic and isovolumic power, work, and tension. The instantaneous power during auxotonic contractions, represented both as power expended by the contractile elements in extending the series elastic component and as external or fiber shortening power, is plotted against time in a representative experiment in Figure 6. The integral of each power curve represents work performed, the sum of the work done in stretching the series elastic component and fiber shortening work, minus the recoil of the SE component, representing the total CEW (Table II). The proportionally small amount of work done in stretching the series elastic (SE) component was greatly increased during heart failure, the increases averaging $81.4 \%$ of control, whereas circumferential fiber shortening (CF) work diminished by an average of $15 \%$. Thus, whereas the ratio of internal SE work to external CF work averaged $16 \%$ (range 11 to $28 \%$ ) under relatively normal conditions, in the acutely failing, dilated heart it averaged $34 \%$ (range 25 to $49 \%$ ). When SE work was considered as the work done in stretching the SE component minus the SE recoil work (net SE work, Table II), these ratios were similar, averaging $12 \%$ in the control state and $22 \%$ during failure. The net effect of this rearrangement of internal and external work was that little alteration occurred in the total CEW, which averaged $43.6 \mathrm{~g}-\mathrm{m}$ (range 29.0 to $48.4 \mathrm{~g}-\mathrm{m}$ ) in the control state and $42 \mathrm{~g}-\mathrm{m}$ (range 28.7 to $47.4 \mathrm{~g}-\mathrm{m}$ ) during heart failure. 


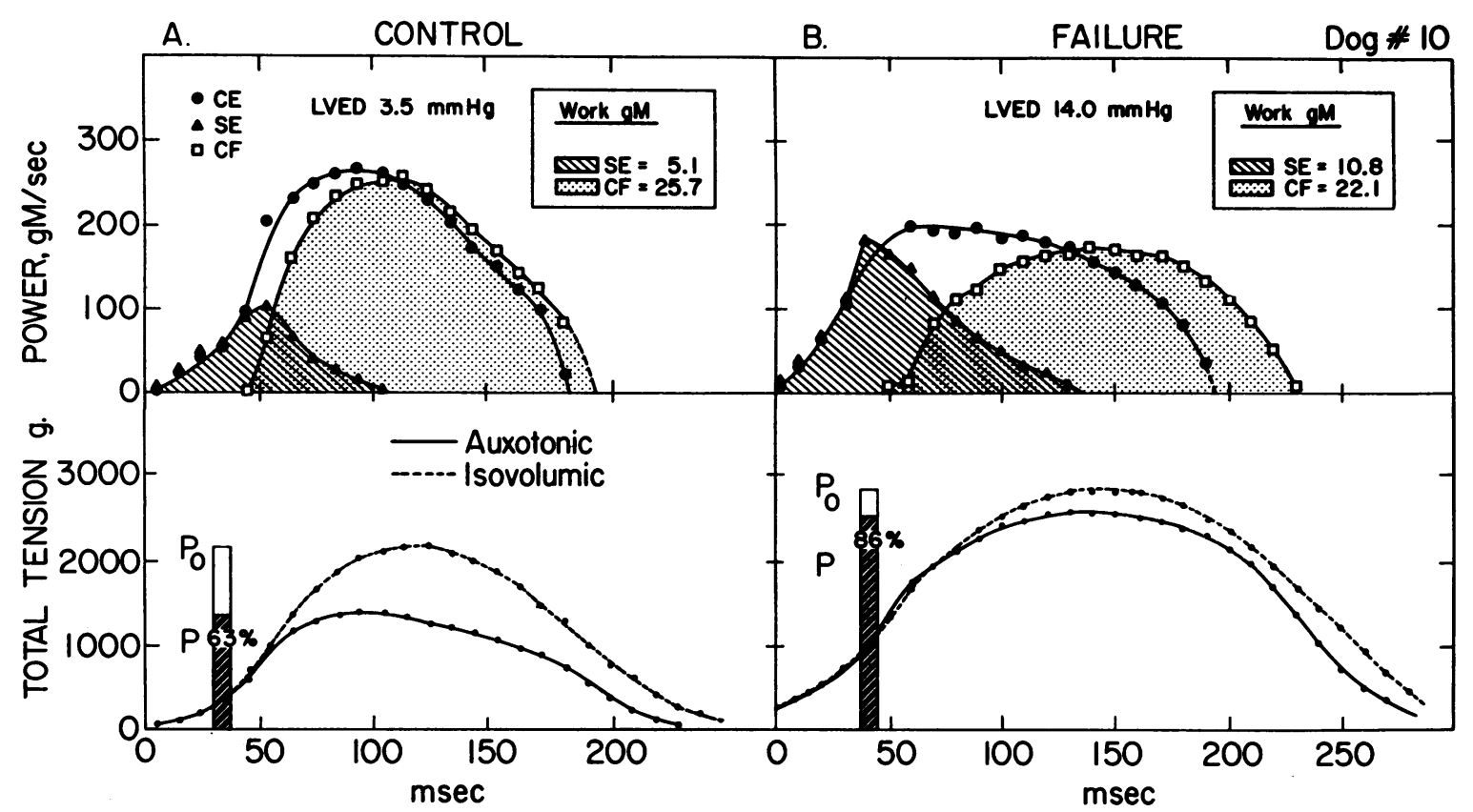

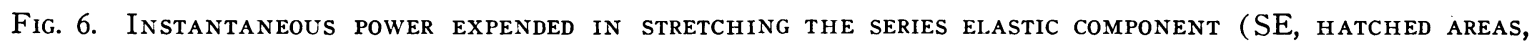
UPPER PANELS) AND IN CIRCUMFERENTIAL FIBER SHORTENING (CF, DOTTED AREAS, UPPER PANELS); THEIR SUM REPRESENTING instantaneous contractile element POWER (CE, closed CirCles). The areas under these curves represent work, shown in the inserts. In the lower two panels, the instantaneous tensions throughout the two auxotonic contractions shown in the upper panels are connected by a solid line, in the control state (panel A) and failure (panel B). The dotted lines show the course of tension for isovolumic contractions originating from the same LVED pressures. The bars illustrate the change in the ratio of maximal auxotonic tension ( $P$ ) to maximal isovolumic tension $\left(\mathrm{P}_{0}\right)$, the ratio being indicated by the percentage figure.

Maximal contractile element power was always reduced by acute heart failure when end-diastolic volume was elevated, averaging $40 \mathrm{~g}-\mathrm{m}$ per second (range 27 to $51 \mathrm{~g}-\mathrm{m}$ per second) during the control period and $28 \mathrm{~g}-\mathrm{m}$ per second (range 20 to $33 \mathrm{~g}-\mathrm{m}$ per second) during failure. During the control state, maximal contractile element power was achieved near peak tension and was mainly composed of external (fiber shortening) power. In the failing heart, maximal power was always reached before peak tension; thus, internal power expended in stretching the series elastic component, expressed as tension, provided a greater contribution to the peak power (Figure 6).

The ratio of maximal tension during ejection (P) to maximal tension developed in isovolumic beats $\left(\mathrm{P}_{0}\right)$ originating from the same LVEDP was always increased by acute failure (Figure 6, Table II). During control conditions, $\mathrm{P} / \mathrm{P}_{0}$ averaged $59 \%$ (range 46 to $67 \%$ ), but during acute heart failure this ratio averaged $76 \%$ (range 66 to $90 \%)$.

\section{Discussion}

Previous studies concerned with ventricular contraction in acute, experimental cardiac failure were concerned largely with the relations between ventricular filling pressure, or volume, and the external cardiac work. Such studies have shown that spontaneous ventricular failure in the dog heartlung preparation may be associated with an increased filling pressure or diastolic volume and unchanged or diminished cardiac output and work $(1,15,16)$; at controlled diastolic volume, external work diminishes (17), and later studies have demonstrated that when left ventricular end-diastolic volume is held constant, a reduction in stroke volume and work occurs (18). In experimental heart failure in the intact $\operatorname{dog}(19)$ and in heart failure in man (20) a smaller stroke volume may be associated with an increased diastolic volume, and geometrical considerations therefore imply that delivery of a smaller stroke volume from the same or a larger spherical volume must be associated with a reduction in the extent of shortening 
of the circumference; further, geometrical factors necessitate that maintenance of systolic ventricular pressure in the face of an enlarged chamber volume results in increased wall tension (21). Finally, several studies have indicated that in the failing ventricle the rate of pressure development during the isometric phase of contraction may be reduced $(22,23)$ and that the time to maximal rate of pressure development may be increased (24).

The present techniques were developed to allow a more complete mechanical analysis of the acutely failing left ventricle. Several advantages accrue from this type of analysis: First, examination of the heart in terms of its muscle mechanics should permit identification of normal and abnormal myocardial function when other problems, such as mechanical valvular defects, coexist; second, these techniques have been shown previously to be more sensitive than standard hemodynamic measures, such as the ventricular function curve, in detecting changes in ventricular contractile state (7) ; third, use of the model for muscle developed by Hill (10) allows insight into features of contractile element behavior that are not reflected in external cardiac dynamics; fourth, the methods should permit normalization and comparison of length-tension and tension-velocity relations among individuals and groups within a species; and finally, the techniques are applicable in the intact, unanesthetized animal (25) and appear to be at least partially feasible in man (26).

We recognize that the use of a simplified geometric model introduces certain problems; thus, the characteristics of the series elastic component of the intact heart have not yet been investigated during various interventions, the intact ventricle is not uniform in shape, and there is little information concerning the distribution of myocardial wall tension in the intact heart. The stiffness of the series elastic component does not appear to change with inotropic interventions in the isolated papillary muscle $(27,28)$, although alterations may be induced with large changes in resting muscle length (28). Use of models other than the sphere may not introduce major changes in calculated volume and tension (29), and, moreover, it is well known that the dilated ventricle tends to become more spherical in shape. Therefore, although more complex models will become necessary as the body of information concerning the intact heart increases, we do not believe that the potential limitations presently visualized seriously impair the advantages of the present methods over earlier hemodynamic techniques.

Interpretation of the experimental results can be framed usefully by referring to the three dimensional, schematic representation of ventricular contraction shown in Figure 7, a model somewhat similar to that suggested by Fry (30) and recently utilized in reference to the behavior of isolated cardiac muscle (31). The normal contraction pattern is shown in Figure 7A; for simplicity, fiber length (the internal equator), rather than contractile element length has been represented on the horizontal plane. During the control beat, shortening of the contractile elements starts on the vertical, posterior plane and during the isovolumic phase of contraction reaches the tension-velocity curve appropriate to that end-diastolic fiber length until the onset of ejection (point B). During ejection a loop is described (4) that reaches point $\mathrm{C}$ at the end of external fiber shortening; point $\mathrm{C}$ lies near the length-tension curve (horizontal plane), presumably close to that point on the curve corresponding to $\mathrm{P}_{0}$ for the instantaneous fiber length at end ejection; the latter supposition, although applicable to isolated muscle $(31,32)$, has not yet been established in the intact heart.

When end-diastolic fiber length is constant (Figure 7B), the length-tension curve is shifted downward during acute heart failure, and from the same end-diastolic fiber length, isovolumic tension $\left(\mathrm{P}_{0}\right)$ is reduced. The isovolumic tensionvelocity relation is also shifted downward and to the left (dotted line). The loop of fiber shortening during ejection (points $\mathrm{B}$ to $\mathrm{C}$, Figure 7B) further indicates that both the speed and extent of shortening at similar wall tensions are reduced from a constant end-diastolic fiber length. Since $\mathrm{P}_{0}$ is considerably reduced during failure whereas maximal tension during ejection is relatively well maintained, the ratio $P / P_{0}$ is increased.

When ventricular end-diastolic fiber length is increased during acute failure, the alteration in ventricular contraction becomes more complex (Figure 7C). It has previously been shown (4) that the heart operating from an increased enddiastolic fiber length follows a tension-velocity relation in which $\mathrm{V}_{\max }$ is unchanged from control, 


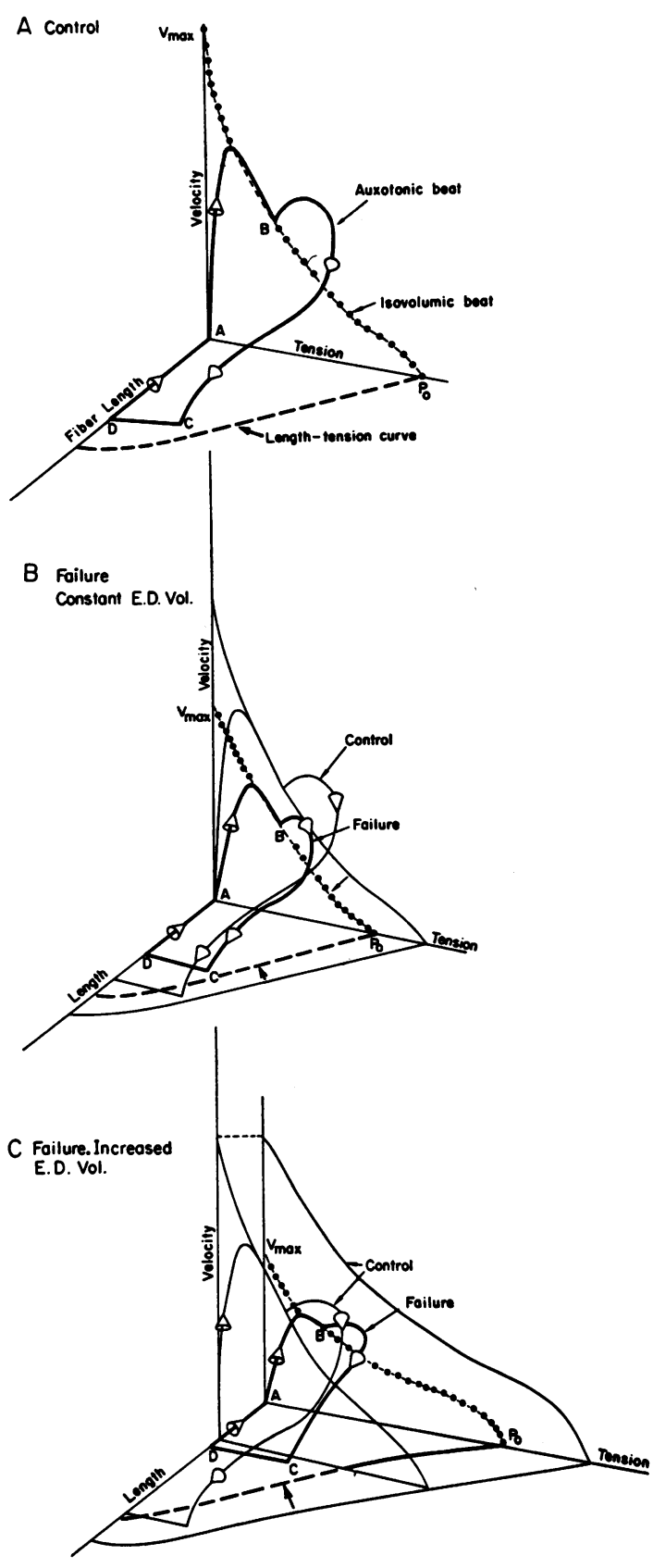

Fig. 7. Three dimensional diagram of the RELATIONS BETWEEN FIBER LENGTH OF THE LEFT VENTRICLE (HORIZONTAL PLANE, FIBER LENGTH INCREASING IN THE POSTERIOR DIRECTION), WALL TENSION, AND VELOCITY OF THE CONTRACTILE ELEMENTS (POSTERIOR, VERTICAL PLANE). $A$ ) The control state is shown; it is also represented in both $B$ and $C$ by the light, solid lines. Onset of contraction is always represented by point $A$, onset and end of ejection by points $B$ and $C$, respectively, and the end of isovolumic relaxation by point D. $B$ ) The heavy vector line indicates the pattern of contraction during failure when end-diastolic volume (ED vol) is held constant but $\mathrm{P}_{0}$ is substantially increased, lying higher on the normal length-tension curve, as illustrated in Figure 7C. In the failing heart, it was shown that $\mathrm{V}_{\max }$ is diminished, whereas $\mathrm{P}_{0}$ is usually little changed from control (heavy dotted line, Figure 7C), the latter finding indicating that the length-tension curve is depressed (heavy dashed line, Figure 7C) ; since, with failure, tension during ejection reaches higher levels than control, the normally large reserve between maximal auxotonic and maximal isovolumic tension is invaded substantially during failure, as reflected in the elevated ratios of $P$ to $P_{0}$. It was also shown that during failure the rate of circumferential fiber shortening is always well below control at comparable wall tensions and that the extent of fiber shortening is reduced (points $\mathrm{B}$ to $\mathrm{C}$, Figure $7 \mathrm{C}$ ). Thus, the elevation of ventricular end-diastolic fiber length, coupled with the reduction in shortening, places point $\mathrm{C}$ near the depressed lengthtension curve. Despite these abnormalities, the increase in diastolic fiber length allows preservation of the stroke volume as well as the intravascular pressure.

We observed that an important change in the pattern of contractile element work accompanies acute heart failure (Figure 6), total work being little changed and internal work increased, but external or fiber shortening work reduced (areas under shortening loops, horizontal plane, Figure 7C). This finding is of interest relative to studies that have shown almost normal oxygen consumption, with a reduction in external cardiac efficiency in heart failure $(18,33)$. When fiber shortening, rather than stroke volume, is used in the calculation of external work, a marked reduction in "external" efficiency can clearly occur even when stroke volume and mean aortic pressure are constant (Figure 6). If myocardial $\mathrm{O}_{2}$ consumption is closely associated with contractile element work, as recently suggested by Britman and Levine (11), it is possible that efficiency relative to $\mathrm{CEW}$ could remain relatively constant despite reductions in the stroke volume and "external" efficiency.

(point A). C) The heavy vector line represents a contraction during failure when end-diastolic volume is augmented; note that the vertical plane is positioned more posteriorly, and the contraction is therefore originating from a larger end-diastolic fiber length (point A). For further details see Discussion. 
Although time is not considered directly in the present three dimensional representation, achievement of maximal $\mathrm{V}_{\mathrm{CE}}$ and peak isovolumic tension is delayed during failure (Figure 3 ). It has been shown in isolated cardiac muscle that inotropic influences that increase active state intensity result in a reduction in time to maximal isometric tension $(34,35)$; these agents produce similar effects on the time to maximal isovolumic tension in the intact heart $(7,36)$. The opposite effects produced by negative inotropism in acute heart failure suggest that in the intact heart, intensity of active state is reciprocally coupled with its rate of onset and duration. It is of interest that despite prolongation of contraction the extent of fiber shortening is always reduced during failure and $\mathrm{P}_{0}$ in isovolumic beats is diminished. An important implication of this finding is that limitation of the time available for contraction is not likely to be related causally to the reduced extent of fiber and contractile element shortening in failure; however, it also appears that the onset of contractile activity is slower in failure (Figure 3 ), and, given a lower intrinsic $\mathrm{V}_{\mathrm{CE}}$, tension development and external shortening could still be more time limited than normally, despite prolongation of contraction. In this connection, it has recently been suggested that in view of the apparently slow onset of active state in cardiac muscle $(34,35)$, active state intensity is probably never much higher than peak isometric tension (37). Two factors may operate to prolong isovolumic contraction in heart failure: increased tension per se (38), evidenced by the longer duration of isovolumic contractions compared with auxotonic beats (Figures 3 and 6 ), and an intrinsic prolongation of active state associated with negative inotropism and diminished active state intensity.

Potential problems with the measurement of ventricular volume by the present technique have been discussed previously (4). In earlier studies from this labortory, both systolic tension and enddiastolic tension were kept relatively constant during various interventions, and recently we have shown that small changes in ventricular diastolic compliance can result from extension of a series viscous component in heart muscle, induced by increases in systolic tension alone (39) ; stress relaxation of the parallel viscous components of heart muscle at high diastolic pressures is also well known (40). Since, in the present experiments, systolic tension was occasionally altered to a minor degree, and, in some experiments, substantial increases in end-diastolic volume occurred, potential errors in the calculation of volume from the pressure-volume relation in the arrested heart must be considered (41). In previous studies in the intact left ventricle contracting isovolumically, large increases (24 to $77 \mathrm{~mm} \mathrm{Hg}$ ) in peak systolic pressure were necessary to induce small reductions (range 0.5 to $1.5 \mathrm{~mm} \mathrm{Hg}$ ) in end-diastolic pressure (39), and it seems likely that the minor changes in systolic tension that occurred in the present experiments would not have had an appreciable influence on the diastolic pressure-volume relation. In the range of end-diastolic pressures studied in the present experiments, the effects of diastolic stress relaxation should also be relatively small (39), and, indeed, there is little or no evidence of stress relaxation in the diastolic pressure-volume relation of the arrested heart at pressures below 12 to $14 \mathrm{~mm} \mathrm{Hg}$ (4). However, if transient changes in volume due to these effects did occur, ventricular volume would have been underestimated; thus, calculated tensions during cardiac failure at an elevated end-diastolic pressure would have been somewhat higher than those reported, whereas $V_{C E}$ and $V_{C F}$ would have been lower, thereby magnifying the alterations ascribed to heart failure.

A relatively large degree of pharmacologic depression of the left ventricle was induced in the present experiments in order to draw clear distinctions between the failing and nonfailing states. A quantitative description of cardiac failure with the present techniques must await the definition of the ventricular contractile properties of normal animals under basal control conditions (25). Measurement of the tension-velocity-length relations in abnormal hearts should then prove more sensitive than previous methods for detecting cardiac depression (7) and should provide a more complete description of the contractile state. It is obvious that the present techniques for inducing acute heart failure may not provide a model of contraction analogous to that in naturally occurring heart failure. However, we have recently observed a striking similarity between the findings in the present studies and the patterns of external shortening and the tension development in human subjects 
with myocardial failure, in whom quite different techniques were employed (26). The mechanism by which the barbiturates depress myocardial contraction remains uncertain. There is some evidence supporting the possibility that pentobarbital administration may be associated with membrane stabilization, reduction of the increase in sodium permeability with depolarization, and perhaps diminished inflow of calcium to the contractile sites (42). It is of interest in this connection that reduction. in the contractile force of the isolated papillary muscle may be associated with loss of integrity of the sodium pump (43), and whether abnormalities in membrane function or excitationcontraction coupling are of basic importance in naturally occurring myocardial failure has been subject to speculation (44). Although the mechanisms for the depressant effects of pronethalol also remain uncertain, this drug exerts a directly toxic effect on the myocardium in the doses employed $(12,13)$, and transient heart failure occurs in the intact animal after surgical ablation of the sympathetic nerves (45). Thus, it is likely that withdrawal of sympathetic tone as well as direct effects played a role in producing acute failure in the present experiments. Finally, the mechanics of ventricular contraction in acute heart failure differ from those of naturally occurring heart failure of the chronic overload variety in that compensatory hypertrophy of the ventricular wall is absent; thus, the present studies may provide a model for failure more analogous to that occurring in severe, end-stage cardiac decompensation, when relative dilatation of the ventricular cavity may predominate over hypertrophy.

\section{References}

1. Krayer, O. Versuche am insuffizienten Herzen. Naunyn-Schmiedeberg's Arch. exp. Path. 1931, $162,1$.

2. Sarnoff, S. J., and E. Berglund. Ventricular function. I. Starling's law of the heart studied by means of simultaneous right and left ventricular function curves in the dog. Circulation 1954, 9, 706.

3. Frye, R. L., and E. Braunwald. Studies on Starling's law of the heart. I. The circulatory response to acute hypervolemia and its modification by ganglionic blockade. J. clin. Invest. 1960, 39, 1043.

4. Ross, J., Jr., J. W. Covell, E. H. Sonnenblick, and E. Braunwald. Contractile state of the heart characterized by force-velocity relations in vari- ably afterloaded and isovolumic beats. Circulat. Res. 1966, 18, 149.

5. Ross, J., Jr., J. W. Covell, E. H. Sonnenblick, and E. Braunwald. Force-velocity relations in acute heart failure. Physiologist 1965, 8, 263.

6. Ross, J., Jr., E. H. Sonnenblick, G. A. Kaiser, P. L. Frommer, and E. Braunwald. Electroaugmentation of ventricular performance and oxygen consumption by repetitive application of paired electrical stimuli. Circulat. Res. 1965, 16, 332.

7. Covell, J. W., J. Ross, Jr., E. H. Sonnenblick, and E. Braunwald. Comparison of the force-velocity relation and the ventricular function curve as measures of the contractile state of the intact heart. Circulat. Res. 1966, 19, 364.

8. Fry, D. L., D. M. Griggs, Jr., and J. C. Greenfield, Jr. Myocardial mechanics: tension-velocitylength relationships of heart muscle. Circulat. Res. 1964, 14, 73.

9. Levine, H. L., and N. A. Britman. Force-velocity relations in the intact dog heart. J. clin. Invest. 1964, 43, 1383.

10. Hill, A. V. The heat of shortening and the dynamic constants of muscle. Proc. roy. Soc. B 1938, 126, 136.

11. Britman, N. A., and H. J. Levine. Contractile element work: a major determinant of myocardial oxygen consumption. J. clin. Invest. 1964, 43, 1397.

12. Black, J. W., and J. S. Stephenson. Pharmacology of a new adrenergic beta-receptor-blocking compound (nethalide). Lancet 1962, 2, 311.

13. Koch-Weser, J. Direct and beta adrenergic receptor blocking actions of nethalide on isolated heart muscle. J. Pharmacol. exp. Ther. 1964, 146, 318.

14. Wallis, W. A., and H. V. Roberts. Statistics. A New Approach. Brooklyn, Free Press of Glencoe, 1956, p. 420.

15. Patterson, S. W., and E. H. Starling. On the mechanical factors which determine the output of the ventricles. J. Physiol. (Lond.) 1914, 48, 357.

16. Katz, L. N., and M. Mendlowitz. Heart failure analyzed in the isolated heart circuit. Amer. J. Physiol. 1938, 122, 262.

17. Peters, H. C., and M. B. Visscher. The energy metabolism of the heart in failure and the influence of drugs upon it. Amer. Heart J. 1936, 11, 273.

18. Lorber, V. Energy metabolism of the completely isolated mammalian heart in failure. Circulat. Res. 1953, 1, 298.

19. Wong, M., E. E. Escobar, G. Martinez, and E. Rapaport. Effect of coronary artery embolization on ventricular volumes. Circulat. Res. 1965, 16, 518.

20. Folse, R., and E. Braunwald. Determination of fraction of left ventricular volume ejected per beat and of ventricular end-diastolic and residual volumes. Experimental and clinical observations with a precordial dilution technic. Circulation $1962,25,674$. 
21. Burch, G. E., C. T. Ray, and J. A. Cronvich. The George Fahr lecture: certain mechanical peculiarities of the human cardiac pump in normal and diseased states. Circulation 1952, 5, 504.

22. Wiggers, C. J. Dynamics of ventricular contraction under abnormal conditions. Circulation 1952, 5 , 321.

23. Gleason, W. L., and E. Braunwald. Studies on the first derivative of the ventricular pressure pulse in man. J. clin. Invest. 1962, 41, 80.

24. Siegel, J. H., and E. H. Sonnenblick. Quantification and prediction of myocardial failure. Arch. Surg. 1964, 89, 1026.

25. Taylor, R. R., J. W. Covell, J. Ross, Jr., and E. H. Sonnenblick. Myocardial force-velocity-length characteristics in the intact, unanesthetized dog (abstract). Circulation 1966, 34 (suppl. 3), 227.

26. Gault, J. H., J. Ross, Jr., E. H. Sonnenblick, and E. Braunwald. Characterization of myocardial contractility in patients with and without cardiac dysfunction by the instantaneous tension-velocity relation (abstract). Circulation 1966, 34 (suppl. 3), 108.

27. Abbott, B. C., and W. F. H. M. Mommaerts. A study of inotropic mechanisms in the papillary muscle preparation. J. gen. Physiol. 1959, 42, 533.

28. Parmley, W. W., and E. H. Sonnenblick. Series elasticity in heart muscle: its relation to contractile element velocity and proposed muscle models. Circulat. Res. In press.

29. Gorlin, R., E. L. Rolett, P. M. Yurchak, and W. C. Elliott, and appendix in collaboration with F. J. Lane and R. H. Levy. Left ventricular volume in man measured by thermodilution. J. clin. Invest. 1964, 43, 1203.

30. Fry, D. L. Discussion. Fed. Proc. 1962, 21, 991.

31. Sonnenblick, E. H. Instantaneous force-velocitylength determinants in the contraction of heart muscle. Circulat. Res. 1965, 16, 441.

32. Abbott, B. C., and D. R. Wilkie. The relation between velocity of shortening and the tensionlength curve of skeletal muscle. J. Physiol. (Lond.) 1953, 120, 214.

33. Blain, J. M., H. Schafer, A. L. Siegel, and R. J. Bing. Studies on myocardial metabolism. VI.
Myocardial metabolism in congestive failure. Amer. J. Med. 1956, 20, 820.

34. Sonnenblick, E. H. Determinants of active state in heart muscle: force, velocity, instantaneous muscle length, time. Fed. Proc. 1965, 24, 1396.

35. Brady, A. J. Time and displacement dependence of cardiac contractility: problems in defining the active state and force-velocity relations. Fed. Proc. 1965, 24, 1410.

36. Siegel, J. H., and E. H. Sonnenblick. Isometric time-tension relationships as an index of myocardial contractility. Circulat. Res. 1963, 12, 597.

37. Brady, A. J. The development of tension in cardiac muscle in Pharmacology of Cardiac Function, Otto Krayer, Ed. Boston and New York, MacMillan, 1964, p. 15.

38. Hill, A. V. The effect of tension in prolonging the active state in a twitch. Proc. roy. Soc. B 1964, 159, 589.

39. Sonnenblick, E. H., J. W. Covell, and J. Ross, Jr. Force dependent hysteresis of a viscous series component in heart muscle. Fed. Proc. 1966, 25, 381.

40. Lundin, G. Mechanical properties of cardiac muscle. Acta physiol. scand. 1944, 7 (suppl. 20).

41. Gilmore, J. P., and R. H. McDonald. Physical factors during homeometric autoregulation. Fed. Proc. 1966, 25, 469.

42. Daniel, E. E., P. K. Johnston, and J. G. Foulks. The mechanism of the effects of sodium pentobarbital and norepinephrine on isolated cardiac muscle. Arch. int. Pharmacodyn. 1962, 138, 276.

43. Langer, G. A. Sodium exchange in dog ventricular muscle and its relation to frequency of contraction (abstract). Fed. Proc. 1966, 25, 518.

44. Mommaerts, W. F. H. M., and G. A. Langer. Fundamental concepts of cardiac dynamics and energetics in Annual Review of Medicine, Arthur C. Degraff and William P. Creger, Eds. Palo Alto, Annual Reviews, Inc., 1963, vol. 14, p. 261.

45. Willman, V. L., T. Cooper, L. G. Cian, and C. R. Hanlon. Mechanism of cardiac failure after excision and reimplantation of the canine heart. Surg. Forum 1962, 13, 93.

\section{SPECIAL NOTICE TO SUBSCRIBERS}

Post Offices will no longer forward the Journal when you move.

Please notify The Journal of Clinical Investigation, Business Office, 10 Stoughton Street, Boston, Mass. 02118, at once when you have a change of address, and do not omit the Zip Code number. 